NOTA CIENTÍFICA

\title{
GERMINAÇÃO E VIGOR DE SEMENTES DE CAFÉ SUBMETIDAS AO ESTRESSE COM ALUMÍNIO'
}

\section{GERMINATION AND VIGOR OF COFFEE SEEDS SUBMITED TO ALUMINIUM STRESS}

\author{
Célia Maria Peixoto de MACEDO² \\ José Carlos LOPES ${ }^{*}$ \\ José Augusto Teixeira do AMARAL ${ }^{4}$ \\ Aymbiré Francisco Almeida da FONSECA ${ }^{5}$
}

\begin{abstract}
RESUMO
O objetivo deste trabalho foi avaliar a germinação e o vigor de sementes de Coffea arabica cv. Catuaí Amarelo IAC 86 e de C. canephora cv. Apoatã sob diferentes concentrações de alumínio. O delineamento experimental foi o inteiramente casualizado, num arranjo fatorial $(2 \times 5)$, com quatro repetições, correspondendo à duas cultivares e cinco níveis da solução de alumínio, nas concentrações de 0;15; 30; 45 e $60 \mathrm{mg} \mathrm{Al} \mathrm{L}^{-1}$. As sementes foram tratadas com fungicida e semeadas em rolos de papel-toalha, mantidos a $30 \stackrel{\circ}{ } \mathrm{C}$, na ausência de luz. Após 30 dias foram avaliados a germinação e o vigor, pelo teste de comprimento da raiz primária. A germinação e o vigor das sementes da cultivar Catuaí Amarelo IAC 86 não foram influenciados pelo aumento da concentração de alumínio na solução, diferindo significativamente da cultivar Apoatã, que se

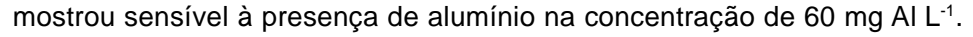

Palavras-chave: Coffea arabica; Coffea canephora; desempenho germinativo; toxicidade.
\end{abstract}

\begin{abstract}
The objective this work was to evaluate the germination and vigour of coffee seed, cultivars Catuaí Amarelo IAC 86 (Coffea Arabica L.) and Apoatã (Coffea canephora Pierre) at different level of Al. The design was it randomized entirely with four repetitions, in a factorial outline two (cultivars) x $5\left(0 ; 15 ; 30 ; 45\right.$ e $\left.60 \mathrm{mg} \mathrm{Al} \mathrm{L}^{-1}\right)$ of Al concentration. The seeds were placed to germinate in paper-towel rolls, incubated under temperature of the $30^{\circ} \mathrm{C}$ and absence of light. After 30 days was determined the germination, and the vigour obtained by the test length of the primary root. The germination and vigour of Catuai Yelow IAC 86 seeds were not influenced by the increase of the aluminum concentration, differing from Apoatã cultivar that the presence of $\mathrm{Al}$ revealed sensible in the concentration of $60 \mathrm{mg} \mathrm{Al} \mathrm{L}^{-1}$.

Key-words: Coffea arabica; Coffea canephora; germination; toxicity.
\end{abstract}

\footnotetext{
1 Parte da dissertação de mestrado do primeiro autor.

${ }^{2}$ Engenheira Agrônoma, Mestre em Produção Vegetal. Departamento de Produção Vegetal, Centro de Ciências Agrárias da Universidade Federal do Espírito Santo - CCA-UFES, Cx. Postal 16, 29500-000, Alegre (ES). E-mail: celiampm@yahoo.com.br, Bolsista FAPES/CAPES.

${ }^{3}$ Engenheiro Agrônomo, Doutor em Fisiologia Vegetal, Professor do Departamento de Produção Vegetal, CCA-UFES, Cx. Postal 16, 29500-000, Alegre (ES). E-mail: jcufes@bol.com.br. Autor para correspondência.

${ }^{4}$ Engenheiro Agrônomo, Doutor em Fisiologia de Culturas, Professor do Departamento de Produção Vegetal, CCA-UFES, Cx. Postal 16, 29500000, Alegre (ES). E-mail: jata@cca.ufes.br.

${ }^{5}$ Engenheiro Agrônomo, Doutor em Fitotecnia, Pesquisador EMBRAPA / INCAPER, Rodovia BR 262, km 94 - Regional Centro Serrano, 29375000, Venda Nova do Imigrante (ES). E-mail: aymbire@incaper.es.gov.br.
} 


\section{INTRODUÇÃO}

O Brasil é o maior produtor mundial de café, responsável por cerca de $30 \%$ do mercado internacional, cujas áreas cafeeiras concentram-se no centro-sul do país, destacando-se os Estados de Minas Gerais, Espírito Santo, São Paulo e Paraná e, em menor quantidade, nas regiões Nordeste e Norte (ABIC, 2006).

O Espírito Santo, localizado em região com grande diversidade climática, cultiva as duas principais espécies de café exploradas comercialmente no mundo: Coffea canephora, em regiões com temperatura média anual de $22-26{ }^{\circ} \mathrm{C}$, com altitudes inferiores a $400 \mathrm{~m}$ e, Coffea arabica, em regiões com temperaturas médias de $19-22^{\circ} \mathrm{C}$, com altitudes superiores a 450-500 m (FERRÃO et al., 2004; MATIELLO et al., 2004).

A cultivar Catuaí Amarelo IAC 86 é suscetível à ferrugem, apresenta ampla capacidade de adaptação na maioria das regiões de plantio de café arábica no Espírito Santo, e por apresentar porte baixo, permite maior densidade de plantio, facilitando a colheita e reduzindo custos com tratamentos fitossanitários (FERRÃO et al., 2004), enquanto o Apoatã é uma cultivar da espécie $C$. canephora, que se apresenta como vigorosa, produtiva, rústica, com sementes graúdas, alta resistência a nematóides e à ferrugem das folhas, sendo muito utilizada para a técnica da enxertia, como "cavalo" para a espécie de $C$. arabica em regiões onde a ocorrência de nematóides é importante (FAZUOLI, 1999; FONSECA et al., 2002).

A natureza do solo freqüentemente afeta a germinação (MAYER e POLJAKOFF-MAYBER, 1989). A toxicidade de alumínio é o fator limitante mais importante para o crescimento das plantas em solos muito ácidos (LOPES et al., 1998), e o alumínio trocável interfere no desenvolvimento da planta reduzindo a germinação de algumas espécies (CUSTÓDIO et al., 2002). As membranas celulares alteram-se quando expostas à concentrações de $\mathrm{Al}$, aumentando sua permeabilidade, culminando com efluxo de solutos do interior, e ocorre a peroxidação lipídica, como sendo um dos primeiros efeitos sobre a bicamada. O potencial elétrico da parede é alterado, e o $\mathrm{Al}$ atua degenerando os canais das proteínas de membranas (SHOMER et al., 2003; VITORELLO et al., 2005).

O sintoma mais facilmente reconhecido da toxicidade de alumínio é a inibição do crescimento da raiz, que é utilizado como um indicativo do estresse da planta a esse elemento (DELHAIZE e RYAN, 1995). Porém, o efeito estimulatório do alumínio em baixas concentrações foi descrito por FREIRE et al. (1987) e BALIGAR et al. (1990).

A toxicidade do alumínio em mudas de cafeeiro já foi discutida em outros trabalhos (BRACCINI et al., 1998; BRACCINI et al., 2000; KONRAD et al., 2005). Porém, há poucos trabalhos disponíveis sobre a influência do alumínio na germinação de sementes do café.

Diante disso, o objetivo deste estudo é avaliar a germinação e o vigor das sementes de C. arabica cv. Catuaí Amarelo IAC 86 e de C. canephora cv. Apoatã em diferentes concentrações de alumínio.

\section{MATERIAL E MÉTODOS}

Este trabalho foi conduzido no Laboratório de Tecnologia e Análise de Sementes do Departamento de Produção Vegetal do Centro de Ciências Agrárias da Universidade Federal do Espírito Santo, CCA-UFES, em Alegre-ES. Foram utilizadas sementes de Coffea arabica L. Cv. Catuaí Amarelo IAC 86 e Coffea canephora Pierre ex Froener cv. Apoatã, provenientes do Instituto Capixaba de Pesquisa, Assistência Técnica e Extensão Rural - INCAPER, em Venda Nova do Imigrante-ES e em Marilândia-ES. As sementes foram colhidas em junho/julho de 2005, acondicionadas em embalagens de plástico semipermeável e armazenadas em geladeira ( $3 \pm 1$ ${ }^{\circ}$ C) até o mês de agosto do mesmo ano, quando foi realizada a semeadura.

Utilizou-se o delineamento inteiramente casualizado, com quatro repetições de 25 sementes. Os tratamentos foram distribuídos no esquema fatorial $2 \times 5$, composto por duas cultivares de café (Catuaí Amarelo IAC 86 e Apoatã) e cinco concentrações de Al $\left(0 ; 15 ; 30 ; 45\right.$ e $\left.60 \mathrm{mg} \mathrm{L}^{-1}\right)$ na forma de $\mathrm{Al}_{2}\left(\mathrm{SO}_{4}\right)_{3} .16 \mathrm{H}_{2} \mathrm{O}$.

A solução nutritiva foi composta de $\mathrm{MgSO}_{4}$ $0,1 \mathrm{mmol} \mathrm{L}^{-1}, \mathrm{KNO}_{3} 0,1 \mathrm{mmol} \mathrm{L}^{-1}, \mathrm{NH}_{4} \mathrm{NO}_{3} 0,15 \mathrm{mmol}$ $\mathrm{L}^{-1}$ e $\mathrm{KHC}_{8} \mathrm{H}_{4} \mathrm{O}_{8} 8,0 \mathrm{mmol} \mathrm{L} \mathrm{L}^{-1}$ (bifitalato de potássio para manter o pH em torno de 4,0), além das diferentes concentrações de Al dos tratamentos. Antes da semeadura as sementes foram tratadas com Captan a 0,1\% por 3 min.

Após a retirada dos pergaminhos, as sementes tiveram avaliados o grau de umidade, com o teor de água ajustado para 14\% (BRASIL, 1992); a germinação, com quatro repetições de 25 sementes por tratamento, distribuídas entre três folhas de papel para germinação, umedecidas, na proporção de 2,5 vezes o seu peso, com solução nutritiva contendo as diferentes concentrações de alumínio. Os rolos foram colocados na posição vertical dentro de recipientes plásticos com uma lâmina de solução nutritiva nas diferentes concentrações de alumínio, para manter a base dos rolos umedecida. Os recipientes foram mantidos no escuro, em câmara BOD sob temperatura constante de $30 \pm 1 \stackrel{\circ}{\circ}$. A germinação foi avaliada aos 30 dias após a semeadura (BRASIL, 1992), considerandose germinadas as sementes que apresentavam protrusão da raiz primária com $2 \mathrm{~mm}$ de comprimento; concomitantemente com o teste de germinação, foi avaliado o vigor das sementes pelo teste de crescimento da raiz (CARVALHO e NAKAGAWA, 2000), aos 40 dias após a semeadura, com o auxílio de uma régua milimetrada.

Os resultados foram submetidos à análise de variância e, quando significativos, as médias foram comparadas pelo teste de Tukey a $5 \%$ de probabilidade, utilizando-se o software estatístico SAEG, versão 9.0 (EUCLYDES, 2004). 


\section{RESULTADOS E DISCUSSÃO}

A análise de variância revelou diferenças significativas $(P<0,05)$ para as características analisadas e a existência de interação significativa entre as cultivares de café e os níveis de alumínio estudados (Tabela 1).

A germinação (Tabela 2) foi diferente entre as cultivares em todas as concentrações de alumínio testadas. As sementes da cv. Catuaí Amarelo IAC 86 apresentaram maior desempenho germinativo que as da cv. Apoatã, porém, essa resposta está relacionada às características intrínsecas das sementes dessas cultivares sendo evidenciada no tratamento sem alumínio. Ao analisar cada cultivar nas diferentes concentrações de alumínio, a cv. Apoatã apresentou menor desempenho germinativo na presença de alumínio na concentração de $60 \mathrm{mg} \mathrm{Al} \mathrm{L}^{-1}$, enquanto não houve diferença significativa entre as concentrações estudadas para a cv. Catuaí Amarelo IAC 86, evidenciando que o alumínio prejudica a germinação da cv. Apoatã. Essa diferença entre as duas cultivares em relação aos níveis de alumínio sugere a existência de algum mecanismo de tolerância nas sementes da cultivar Catuaí Amarelo IAC 86. Diversos mecanismos bioquímicos têm sido propostos para explicar a tolerância ao alumínio em plantas. No caso da tolerância interna, à raiz, de acordo com ABICHEQUER et al. (2003), são citadas: a ação de polipeptídeos do citoplasma como moléculas quelantes; a existência de enzimas, cuja atividade não é prejudicada pelo alumínio e a eliminação do alumínio do ambiente celular por compartimentalização no vacúolo. $\mathrm{E}$, de acordo com LARCHER (2000), os compostos de alumínio são facilmente solubilizados em condições ácidas atuando sobre o metabolismo de minerais e sobre o vigor das plantas.

TABELA 1 - Resumo da análise de variância para a germinação e comprimento da raiz primária de plântulas de sementes das cultivares Catuaí Amarelo IAC 86 e Apoatã em diferentes concentrações de alumínio em solução.

\begin{tabular}{lccc}
\hline \multicolumn{1}{c}{ FV } & \multirow{2}{*}{ GL } & \multicolumn{2}{c}{ Quadrados Médios } \\
\cline { 3 - 4 } & & Germinação $(\%)$ & $\mathrm{CRP}^{1}(\mathrm{~cm})$ \\
\hline Cultivares & 1 & $2788,9^{*}$ & $3,48^{*}$ \\
Alumínio & 4 & $129,1^{*}$ & $1,65^{*}$ \\
Cultivar x alumínio & 4 & $99,9^{*}$ & $1,03^{*}$ \\
Resíduo & 30 & 31,8 & 0,23 \\
Total & 39 & - & - \\
\hline Valores mínimos & - & 72 & 2,07 \\
Valores máximos & - & 100 & 4,80 \\
CV (\%) & - & 6,4 & 13,1 \\
\hline
\end{tabular}

* Significativo a $5 \%$ de probabilidade pelo teste $\mathrm{F} . \mathrm{FV}=$ Fonte de variação. $\mathrm{GL}=\mathrm{Grau}$ de liberdade. $\mathrm{CV}=$ Coeficiente de variação. CRP = comprimento de raiz primária.

TABELA 2 - Germinação e comprimento da raiz primária de plântulas de sementes das cultivares Catuaí Amarelo IAC 86 e Apoatã em diferentes concentrações de alumínio em solução.

\begin{tabular}{lccccc}
\hline \multirow{2}{*}{ Cultivar } & \multicolumn{6}{c}{ Concentração de alumínio $\left(\mathrm{mg} \mathrm{L}^{-1}\right)$} \\
\cline { 2 - 5 } & \multicolumn{6}{c}{15} & \multicolumn{6}{c}{ Germinação (\%) } & 45 & 60 \\
\hline IAC 86 & $98 \mathrm{aA}$ & $96 \mathrm{aA}$ & $95 \mathrm{aA}$ & $97 \mathrm{aA}$ & $96 \mathrm{aA}$ \\
Apoatã & $86 \mathrm{bA}$ & $77 \mathrm{bAB}$ & $81 \mathrm{bA}$ & $86 \mathrm{bA}$ & $68 \mathrm{bB}$ \\
\hline \multicolumn{7}{c}{ Comprimento da raiz primária de plântulas (cm) } \\
\hline IAC 86 & $2,93 \mathrm{aB}$ & $4,29 \mathrm{aA}$ & $4,28 \mathrm{aA}$ & $4,07 \mathrm{aA}$ & $4,12 \mathrm{aA}$ \\
Apoatã & $3,07 \mathrm{aBC}$ & $2,97 \mathrm{bBC}$ & $3,84 \mathrm{aAB}$ & $4,10 \mathrm{aA}$ & $2,76 \mathrm{bC}$ \\
\hline
\end{tabular}

${ }^{1}$ Médias seguidas de mesma letra, maiúscula na linha e minúscula na coluna, não diferem entre si pelo teste de Tukey a $5 \%$. DMS para germinação: Linha =11,57 e Coluna =8,15. DMS para CRP: Linha $=0,98$ e Coluna $=0,69$. DMS = diferença mínima significativa.

Dentro de cada tratamento com alumínio, a diferença do comprimento da raiz primária entre cultivares foi observada na concentração de $60 \mathrm{mg}$ Al $\mathrm{L}^{-1}$, onde a cultivar Catuaí Amarelo IAC 86 apresentou maior comprimento de raiz. Esse resultado sugere que as concentrações de alumínio utilizadas foram baixas, não apresentando efeito "drástico" no crescimento das raízes das plântulas na maior concentração de alumínio. Além disso, cada cultivar apresentou uma resposta diferenciada em relação às diferentes concentrações de $\mathrm{Al}^{3+}$. $\mathrm{Na}$ ausência deste elemento, a cultivar Catuaí Amarelo IAC 86 apresentou menor comprimento da raiz primária, enquanto a cultivar Apoatã apresentou a mesma resposta em concentração de $60 \mathrm{mg} \mathrm{Al} \mathrm{L}^{-1}$. Para a cultivar Catuaí Amarelo IAC 86, todos os tratamentos com alumínio não diferiram entre si, observando-se um acréscimo no comprimento da raiz primária, possivelmente por interferir na homeostase de $\mathrm{Ca}^{2+}$, ou por se ligar intimamente 
MACEDO, C.M.P. et al. Germinação e vigor de sementes de café...

ao DNA (VITORELLO et al., 2005), sugerindo que o $\mathrm{Al}^{3+}$ nessas concentrações não seja tóxico a essa cultivar. Concentrações baixas de $\mathrm{Al}^{3+}$ podem estimular o desenvolvimento inicial do vegetal (SZYMANSKA e MOLAS, 1996), sem causar efeito tóxico, agindo diretamente sobre o alongamento das raízes (MIYASAKA e HAWES, 2001; YAMAMOTO et al., 2002).

A cultivar Apoatã (Tabela 2) apresentou maior aumento do comprimento de raiz nas concentrações de 30 e $45 \mathrm{mg} \mathrm{Al} \mathrm{L}^{-1}$, evidenciando ser sensível à concentração de $60 \mathrm{mg} \mathrm{Al} \mathrm{L}^{-1}$, sugerindo que com a utilização do método do papel-solução, essa concentração de alumínio afeta o desenvolvimento da raiz primária de plântulas de café robusta. A inibição do crescimento da raiz é o sintoma visível mais rápido da toxicidade do alumínio em plantas sensíveis (DEGENHARDT et al.,1998). A cultivar Apoatã apresentou menores comprimentos de raiz nas concentrações de 0 e $15 \mathrm{mg} \mathrm{Al} \mathrm{L}^{-1}$. O efeito da solução com a concentração de $15 \mathrm{mg} \mathrm{Al} \mathrm{L}^{-1}$ não diferiu daquela sem alumínio. A concentração de 15 mg Al L-1 foi considerada muito baixa para causar algum estímulo no crescimento de raízes primárias, ao contrário do efeito benéfico do elemento para 0 Apoatã nas concentrações de 30 e $45 \mathrm{mg} \mathrm{Al} \mathrm{L}^{-1}$.

A diferença de resposta das duas cultivares de café em relação ao Al (Tabela 2) evidencia que a cultivar Catuaí Amarelo IAC 86 apresentou maior resistência a este elemento do que a cultivar Apoatã durante a fase de germinação e, no vigor, observouse que a partir da concentração de $45 \mathrm{mg} \mathrm{Al} \mathrm{L}^{-1}$ foi possível discriminar as duas cultivares quanto à tolerância a esse elemento. Resultados similares foram encontrados por BRACCINI et al. (2000).

\section{CONCLUSÕES}

A germinação e o vigor das sementes da cultivar Catuaí Amarelo IAC 86 não foram influenciados pelo aumento da concentração de alumínio na solução, diferindo significativamente da cultivar Apoatã, que se mostrou sensível à presença de alumínio na concentração de $60 \mathrm{mg} \mathrm{Al} \mathrm{L-1}^{-1}$.

\section{AGRADECIMENTO}

À FAPES/CAPES pela concessão de bolsa de mestrado ao primeiro autor.

\section{REFERÊNCIAS}

1. ABIC. História do café. Disponível em: <http://www.abic.com.br/> Acesso em 01 nov 2006

2. ABICHEQUER, A.D.; BOHNEN, H.; ANGHINONI, I. Absorção, translocação e utilização de fósforo por variedades de trigo submetidas à toxidez de alumínio. Revista Brasileira de Ciência do Solo, v. 27, p. 373-378, 2003.

3. BALIGAR, V.C.; ANGHINONI, I.; PITTA, G.V.E.; SANTOS, H.L.; CUNHA FILHO, E; SCHAFFERT, R.E. Efeito de diferentes níveis de alumínio na solução nutritiva sobre a composição da fração nitrogenada em sorgo. Revista Brasileira de Fisiologia Vegetal, v. 2, n. 2, p. 47-52, 1990.

4. BRACCINI, M.C.L.; MARTINEZ, H.E.P.; BRACCINI, A.L. Avaliação de linhagens de cafeeiros quanto à tolerância ao alumínio pelo método do papel-solução. Bragantia, v. 59, n. 2, p. 221-226, 2000

5. BRACCINI, M.C.L.; MARTINEZ, H.E.P.; PEREIRA, P.R.G.; SAMPAIO, N.F.; SILVA, E.A.M. Tolerância de genótipos de cafeeiro ao Al em solução nutritiva. I. Crescimento e desenvolvimento da parte aérea e sistema radicular. Revista Brasileira de Ciência do Solo, v. 22, p. 435-442, 1998

6. BRASIL. Ministério da Agricultura e Reforma Agrária. Regras para análise de sementes. Brasília: SNDA/DNDV/ CLAV, 1992. 365 p.

7. CARVALHO, N.M.; NAKAGAWA, J. Sementes: ciência, tecnologia e produção. 4. ed. Jaboticabal: FUNEP, 2000. $588 \mathrm{p}$.

8. CUSTÓDIO, C.C.; BOMFIM, D.C.; SATURNINO, S.M.; MACHADO NETO, N.B. Estresse por alumínio e por acidez em cultivares de soja. Scientia Agricola, v. 59, n. 1, p. 145-153, 2002.

9. DEGENHARDT, J., LARSEN, P.B., HOWELL, S.H., KOCHIAN, L.V. Aluminum resistance in the Arabidopsis mutant alr104 is caused by an aluminum-induced increase in rhizosphere pH. Plant Physiology, v. 117, p. 19-27, 1998.

10. DELHAIZE, E.; RYAN, P.R. Aluminum toxicity and tolerance in plants. Plant Physiology, v. 107, n. 2, p. 315-321, 1995.

11. EUCLYDES, R.F. Sistema para análises estatísticas e genéticas. Versão 9.0. Viçosa: FUNARBE/UFV, 2004.

12. FAZUOLI, L.C. Cultivares IAC de café. O Agronômico, v. 51, n. 1, 1999. Disponível em:<http://www.iac.sp.gov.br/ OAgronomico/OAgronomico.asp> Acesso em: 11 jul 2007.

13. FERRÃO, M.A.G.; FONSECA, A.F.A.; FERRÃO, R.G.; ROCHA, A.C. Cultivares de café arábica para a região das montanhas do estado do Espírito Santo. Vitória: INCAPER, 2004. 38 p.

14. FONSECA, A.F.A, FERRÃO, R.G., FERRÃO, M.A.G.; BRAGANÇA, S.M.; SILVEIRA, J.S.M. Variedades derivadas de café conillon (Coffea canephora) desenvolvidas pelo INCAPER para o Espírito Santo. In: SIMPÓSIO DE PESQUISA DOS CAFÉS DO BRASIL, 2, 2001, Vitória-ES. Anais. Brasília: EMBRAPA Café, 2002. v. 2. p.1063-1066.

15. FREIRE, L.R.; AMARAL SOBRINHO, N.M.B.; FERNANDES, M.S.; RIBEIRO, M.E.S.; SANTOS, J.C.P. dos. Efeito de alumínio nas raízes de arroz cultivado em solução nutritiva. Pesquisa Agropecuária Brasileira, v. 22, n. 5, p. 459-464, 1987.

16. KONRAD, M.L.F.; SILVA, J.A.B.; FURLANI, P.R.; MACHADO, E.C. Trocas gasosas e fluorescência da clorofila em seis cultivares de cafeeiro sob estresse de alumínio. Bragantia, v. 64, n. 3, p. 339-347, 2005.

17. LARCHER, W. Ecofisiologia Vegetal. São Paulo: Rima Artes e Textos, 2000. 531 p. 
18. LOPES, J.C.; CAPUCHO, M.T.; KROHLING, B.; ZANOTTI, P. Germinação de sementes de espécies florestais de Caesalpinea ferrea Mart. ex Tul. Var. leiostachya Benth., Cassia grandis L. E Samanea saman Merrill, após tratamento para superar a dormência. Revista Brasileira de Sementes, v. 20, n. 1, p. 80-86, 1998.

19. MATIELLO, J.B.; AMARAL, A.S.; MENDONÇA, S.M.; LEITE FILHO, S.; LOUBACK, A. Viabilidade do cultivo de variedades de café arábica em regiões quentes, comparativo com café conilon em dois pisos altitudinais. In: CONGRESSO BRASILEIRO DE PESQUISAS CAFEEIRAS, 30., 2004, São Lourenço. Trabalhos Apresentados. Rio de Janeiro: MAPA/PROCAFE, 2004. p. 15.

20. MAYER, A.M.; POLJAKOFF-MAYBER, A. The germination of seeds. London: Pergamon Press, $1989.270 \mathrm{p}$.

21. MIYASAKA, S.C.; HAWES, M.C. Possible role of border cells in detection and avoidance of aluminium toxicity. Plant Physiology, v. 125, p. 1978-1987, 2001

22. SHOMER, I.; NOVACKY, A.J.; PIKE, S.M.; YERMIYAHU, U.; KINRAIDE, T.B. Electrical potentials of plant cell walls in response to the ionic environment. Plant Physiology, v. 133, p. 411-422, 2003.

23. SZYMANSKA, M.; MOLAS, J. The effect of aluminium on early development stages of Cucumis sativus L. Folia Horticulturae, v. 8, n. 1, p. 73- 83, 1996.

24. VITORELLO, V.A.; CAPALDI, F.R.; STEFANUTO, V.A. Recent advances in aluminium toxicity and resistance in higher plants. Brazilian Journal of Plant Physiology, v. 17, p. 129-143, 2005.

25. YAMAMOTO, Y.; KOBAYASHI, Y.; DEVI, S.R.; RIKIISHI, S.; MATSUMOTO, H. Aluminium toxicity is associated with mitocondrial dysfunction and the production of reative oxygen species in plant cells. Plant Physiology, v. 128, p. 63-72, 2002.

Recebido em 04/10/2007

Aceito em 03/03/2008 
